\title{
A Study of Menstrual Cycle Patterns and Disturbances among psychiatric patients in a tertiary health care institute
}

\author{
Mahemubin S Lahori ${ }^{1}$, Matib M Rangoonwala ${ }^{2}$, Hitendra A Gandhi ${ }^{3}$, \\ Bhaveshkumar M Lakdawala ${ }^{4}$ \\ ${ }^{1}$ Assistant Professor, Department of Psychiatry, GMERS Medical College, Gandhinagar. \\ ${ }^{2}$ Program Officer, Narsinghpur, Jhpiego \\ ${ }^{3}$ Professor and Head, Department of Psychiatry Dept, GCS Medical college, Ahmedabad. \\ ${ }^{4}$ Professor and Head, Department Of Psychiatry, AMC-MET Medical College, Ahmedabad \\ Corresponding author: Dr. Mahemubin Lahori \\ Email-mubinr@gmail.com
}

\begin{abstract}
Background: An understanding of the relationship between psychiatric disorders and menstrual characteristics is important to the assessment and care of the women. Menstrual cycle regularity and length have significant associations with specific current and lifetime psychiatric disorders

Methodology: A cross sectional study was conducted in 100 female patients undergoing psychiatry treatment in department of Psychiatry of tertiary Hospital in Ahmedabad between the age group of 15-50 years with a single diagnosis on Axis-I according to DSM- IV TR and in their reproductive age (menarche to menopause).

Results: Of the 100 female patients interviewed, $22 \%$ reported of menstrual irregularities, $35 \%$ reported of Dysmenorrhoea and 31\% reported of having Pre-menstrual symptoms. Almost half of the patients $(49 \%)$ had Major Depressive Disorder (MDD) and 21\% suffered from Bipolar mood disorder. The menstrual irregularities were observed to be in $28.6 \%$ of patients of Bipolar mood disorder and dysmenorrhoea was most common (53.1\%) among MDD patients.

Conclusions: The present study showed that menstrual irregularities were more common in patients with bipolar mood disorder and dysmenorrhoea was associated more with depressive disorders as compared to psychotic disorders.
\end{abstract}

Key Words: menstrual irregularities, dysmenorrhoea, psychiatric patients, psychotic disorders

(Paper received $-15^{\text {th }}$ December 2017, Peer review completed $-24^{\text {th }}$ December 2017)

(Accepted $-28^{\text {th }}$ December 2017)

\section{INTRODUCTION}

It has long been realized that menstruation and mental illness are linked. As early as 1827 , menstrual mood disorder was used as a defence in filicide [1]. The physiological processes associated with menarche, menstrual cycling, pregnancy, postpartum and menopause occurs within the context of woman's psychological and interpersonal life, interfacing with psychosocial functioning throughout adolescence, young adulthood, midlife and late life. Reproductive events and processes have both physiological and psychosocial concomitants [2].

The traditional medicine separates the treatment of reproductive events and processes from that of psychological functioning. This imposed dichotomy between mind and body undermines the understanding and treatment of both reproductive and psychiatric dysfunction in women. Hence, 
depression during pregnancy and the postpartum period often goes unidentified and under treated leading to negative consequences for the woman and her children, men and society in general [2].

A better understanding of the observed link between mental health and menstrual cycles is critical to the provision of quality care for women. The physiologic basis for women's mental health has begun to be explored, particularly since the success of selective serotonin reuptake inhibitors for depression has highlighted the importance of biological origins of mental illness. Likewise, the course of psychiatric illness may be biologically influenced by the menstrual cycle. It is also possible that menstrual length and irregularity could, in turn, be influenced by mental health. When more is known about the relationships between these two important areas; patient education, clinical screening, and treatment modalities can be more knowledgeably implemented [3].

There has been clear advancement of knowledge with the advent of understanding that female sex hormones underlie the menstrual cycle and that mood disorders related to menstruation are a significant problem for some women [4]. Women's health is escalating in importance in the national health care agenda with new data about gender differences being acquired quickly. Women's health has increasingly become an area of speciality, with residency tracks, fellowships, conferences and organizations dedicated to this important clinical and research focus.

An understanding of the relationship between psychiatric disorders and menstrual characteristics is important to the assessment and care of the women. Menstrual cycle regularity and length have significant associations with specific current and lifetime psychiatric disorders [5].

Consequently, the present study was conducted to study the socio-demographic profiles of the female patients attending the psychiatric clinics, assess the prevalence of menstrual cycle irregularities in psychiatric patients and association between psychiatric diagnosis and menstrual irregularities.

\section{METHODOLOGY}

\section{Setting}

The study was conducted in Sheth V. S. General hospital attached to SMT. NHL Municipal Medical College, Ahmedabad. The hospital is one of the three municipal hospitals of Ahmedabad city.

\section{Study Design and Sampling}

A cross-sectional study was conducted among 100 female patients on psychiatric treatment, the subjects being indoor as well as outdoor patients from the department of psychiatry between 15-50 years of age with inclusion criteria of Patients having single diagnosis on Axis I according to DSM IV TR, in their reproductive age (menarche to menopause) and on psychiatric treatment. The patients who were either pregnant or on oral contraceptive pills were excluded.

\section{Data Collection}

Female patients attending the psychiatric department for treatment purpose within the designated age group were asked about their menstrual status and if they were in their reproductive years between menarche to menopausal state, were informed about the study.

After taking their consent, a detailed interview and evaluation of the subject was carried out using pretested Performa which included the socio-demographic profile of the patient, psychiatric diagnosis and treatment, any concurrent medical illness and menstrual history. The psychiatric diagnosis was confirmed on the basis of structured clinical interview and past history according to DSM- IV TR for both Axis-I and Axis-II.

The patients having amenorrhea were advised for a urine pregnancy test and those found to be positive were not taken in the study. The diagnosis and the treatment history were obtained from the records available with them. 


\section{STATISTICAL ANALYSIS}

The data was entered into MS Excel 2007 and appropriate charts and tables were made. Appropriate statistical tests were applied using Epi Info 7. Descriptive statistics along with frequency and percentages were used where appropriate.

\section{RESULTS}

As shown in table 1, the mean age of the patients was 31.8 years. Majority (64\%) of them were Hindus followed by Muslims (34\%). Out of 100 female patients in the study, 74 were married and 81 were residing in urban areas. $18 \%$ of the patients were not having any children (Table 1).

According to DSM IV TR, almost half (49\%) of them were diagnosed to be of Major Depressive Disorder (MDD). 21 patients were suffering from Bipolar Mood Disorder and 15 were observed to be having psychotic disorder (Figure 1).

Out of the 100 female patients, the duration of illness was less than a year among $1 / 3^{\text {rd }}$ of the patients (33\%). 18 subjects were suffering from the psychiatric disorder since more than 5 years. The most common concurrent physical illnesses observed among the patients were hypothyroidism (4\%) and Epilepsy (3\%) (Table 2). Regarding the menstrual problems in the patients, menstrual irregularities were present in 22 of them. The problem of Dysmenorrhoea was among 35 subjects and 31 of the patients were suffering from the Pre Menstrual symptoms (Table 3).

On comparing the menstrual irregularities with psychiatric diagnosis, it was observed that the menstrual irregularities were present to be more among patients with Bipolar Mood Disorder (28.6\%) and MDD (26.5\%). Only 1 patient (6.6\%) out of 15 with psychotic disorder was found to be suffering from menstrual irregularities (Table 4). More than half of the patients (53.1\%) of MDD were having the problem of dysmenorrhoea whereas it was among $26.6 \%$ of the subjects with Anxiety disorder and in $23.8 \%$ of the patients with Bipolar Mood Disorder. The issue of dysmenorrhoea was not seen among the patients with the psychotic disorder (Table 5).

Table 1 - Socio-demographic characteristics of the patients

\begin{tabular}{|c|c|}
\hline Characteristics & $(\mathrm{N}=100)$ \\
\hline Age group & 20 \\
$15-25$ & 51 \\
$26-35$ & 29 \\
$>35$ & Mean age=31.8 years (Range 15-47 years) SD=7.67 years \\
\hline Religion & 64 \\
Hindu & 34 \\
Muslim & 2 \\
Christian & \\
Domicile & 19 \\
Rural & 81 \\
Urban & \\
Marital status & 74 \\
Married & 13 \\
Unmarried & 09 \\
Divorced & 04 \\
Widow & \\
\hline Parity & 18 \\
0 & 44 \\
1-2 & 38 \\
\hline 3-4 and $>4$ & \\
\hline
\end{tabular}


Figure 1 - Psychiatric diagnosis of the subjects

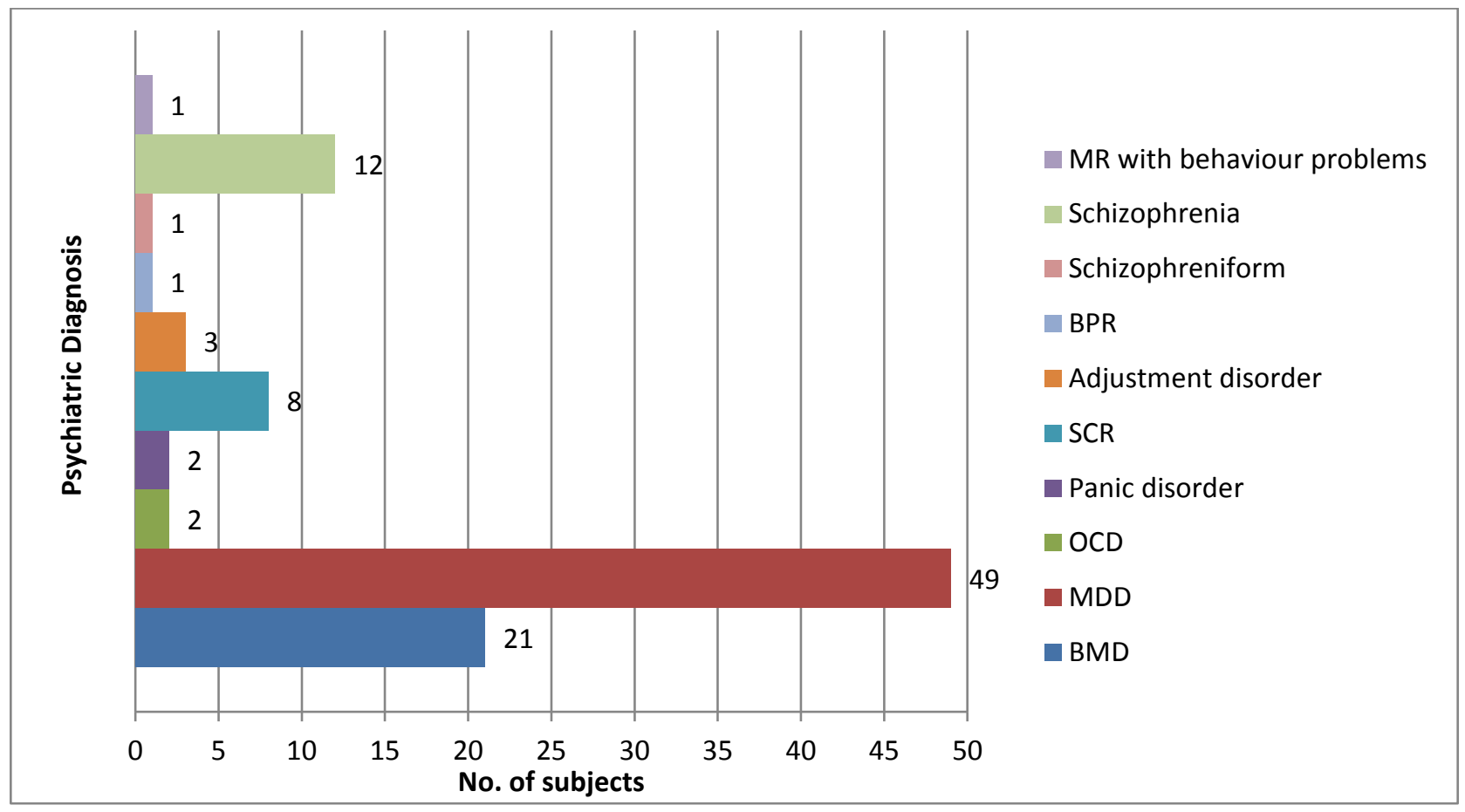

Table 2 - Details regarding Psychiatric diagnosis $(\mathrm{N}=100)$

\begin{tabular}{|c|c|c|}
\hline & No. & Percentage \\
\hline Total duration of illness & 33 & 33 \\
$<1$ year & 49 & 49 \\
$1-5$ years & 18 & 18 \\
$>5$ years & 1 & \\
\hline Concurrent Physical Illness & 1 & 1 \\
DM & 3 & 3 \\
Hypertension & 4 & 4 \\
Epilepsy & & \\
Hypothyroidism & &
\end{tabular}

Table 3 - Menstrual problems in patients $(\mathrm{N}=100)$

\begin{tabular}{|c|c|c|}
\hline Menstrual Problems & No. & Percentage \\
\hline Menstrual irregularity & 22 & 22 \\
Present & 78 & 78 \\
Absent & 35 & 35 \\
\hline Dysmenorrhea & 65 \\
Present & 65 & 31 \\
Absent & 31 & 69 \\
\hline Pre Menstrual Symptoms & 69 & \\
Present & & \\
Absent & & \\
\hline
\end{tabular}


Table 4 - Comparison of menstrual irregularities with psychiatric diagnosis

\begin{tabular}{|c|c|c|c|c|c|}
\hline \multirow{2}{*}{$\begin{array}{c}\text { Menstrual } \\
\text { irregularity }\end{array}$} & \multicolumn{3}{|c|}{ Psychiatric diagnosis } & \multirow{2}{*}{ Total } \\
\cline { 2 - 5 } & $\begin{array}{c}\text { Bipolar mood } \\
\text { disorder n (\%) }\end{array}$ & $\begin{array}{c}\text { MDD } \\
\mathrm{n}(\%)\end{array}$ & $\begin{array}{c}\text { Anxiety } \\
\text { disorder n (\%) }\end{array}$ & $\begin{array}{c}\text { Psychotic } \\
\text { disorder n (\%) }\end{array}$ & \\
\hline Present & $6(28.6)$ & $13(26.5)$ & $2(13.3)$ & $1(06.6)$ & 22 \\
\hline Absent & $15(71.4)$ & $36(73.5)$ & $13(86.7)$ & $14(93.4)$ & 78 \\
\hline Total & $21(100.0)$ & $49(100.0)$ & $15(100.0)$ & $15(100.0)$ & 100 \\
\hline
\end{tabular}

Table 5 - Comparison of Dysmenorrhoea with Psychiatric diagnosis

\begin{tabular}{|c|c|c|c|c|c|}
\hline \multirow{2}{*}{ Dysmenorrhoea } & \multicolumn{4}{|c|}{ Psychiatric diagnosis } & \multirow{2}{*}{ Total } \\
\cline { 2 - 5 } & $\begin{array}{c}\text { Bipolar mood } \\
\text { disorder }\end{array}$ & MDD & $\begin{array}{c}\text { Anxiety } \\
\text { disorder }\end{array}$ & $\begin{array}{c}\text { Psychotic } \\
\text { disorder }\end{array}$ & \\
\hline Present & $5(23.8)$ & $26(53.1)$ & $4(26.6)$ & $0(00.0)$ & 35 \\
\hline Absent & $16(76.2)$ & $23(46.9)$ & $11(73.4)$ & $15(100.0)$ & 65 \\
\hline Total & $21(100.0)$ & $49(100.0)$ & $15(100.0)$ & $15(100.0)$ & 100 \\
\hline
\end{tabular}

\section{DISCUSSION}

An understanding of the relationship between psychiatric disorders and menstrual characteristics is important to the assessment and care of the women. This study has provided the insights into the association between psychiatric illness and menstrual cycle characteristics [6].

The study showed that the menstrual irregularities were more common among patients suffering from Bipolar Mood disorders and MDD as compared to anxiety and psychotic disorders. Various research studies have explored a relationship between depression and menstrual history [7-8]. A study by Alec Coppen suggested a raised prevalence of menstrual disorders in neurotic patients, a normal prevalence in patients suffering from affective disorders and a reduced prevalence in women suffering from schizophrenia [9]. Another study showed that $65 \%$ of the women with Bipolar Mood Disorders were suffering from menstrual irregularities [10].

In a study among the women of reproductive age in rural area in Rajasthan, the prevalence of menstrual irregularity was $6.1 \%$ which is far lesser than in our study subjects. This may suggest that the rate of menstrual cycle disturbances is higher in the psychiatric patients than the general population.

The advances in our understanding of women's health, including the recognition and treatment of psychiatric disorders, will increase the ability to provide comprehensive care to women.

\section{Limitations of the study}

The patients were taken from a single hospital might affect the representativeness of the findings and the women with psychiatric disorder may be less able to accurately describe regarding their menstrual cycle characteristics.

\section{CONCLUSION}

The present study is a step towards the understanding the relationship between menstrual cycle characteristics and specific psychiatric disorders and treatment. Common factors may underlie the pathophysiology of menstrual disturbances and psychiatric disorder such that successful treatment of psychiatric disorder may improve menstrual cycle disturbances and vice-versa. A further understanding of the complexities of this relationship may help to guide the assessment and proper treatment of women in this area.

\section{REFERENCES}


1. Hitzig JE. Mord in einem durch Eintreten des Monatsflusses herbeigefuhrten unfreien Zustande.Hitzig's Zeitschrift fur Kriminalrechtspflege,6.237.(summarizes in Powers, E.F.(1883). Beitrag zur Kenntniss der Menstrualen Psychosen. Inaugral Dissertation,Zurich) ; 1827.

2. Hendrick V, Altshuler LL, Burt VK. Course of psychiatric disorders across the menstrual cycle. Harvard Rev Psychiatry 1996;4(4):200-7.

3. Barron ML, Flick LH,Cook CA,Homan SM,Campbell C., Associations between psychiatric disorders and menstrual cycle characteristics. Arch Psychiatr Nurs 2008;22(5):254-65.

4. Rasgon N, Bauer M, Glenn T, Elman S, Whybrow PC. Menstrual cycle related mood changes in women with bipolar disorder. Bipolar Disord 2003;5(1):48-52.

5. Harlow BL, Wise LA, Otto MW, Soares CN, Cohen LS. Depression and its influence on reproductive endocrine and menstrual cycle markers associated with perimenopause: the Harvard Study of Moods and Cycles. Arch Gen Psychiatry 2003;60:29-36.

6. Bhat VK, Srivastava ON, Gupta S, Prakash A. Personality characteristics of patients attending gynaecological out-patient of a general hospital. Indian J Psychiatry 2010;19:77-81.

7. Rasgon NL, Reynolds MF, Elman S. Saad M, Frye MA: Longitudinal evaluation of reproductive function in women treated for bipolar disorder. J Affective Disord 2005;89:217-23.

8. Cosgrove KP, Mazure CM, Staley JK. Evolving knowledge of sex differences in brain structure, function, and chemistry. Biol Psychiatry 2007;62(8):847-55.

9. Young EA, Midgley AR, Carlson NE, Brown MB. Alteration in the hypothalamic-pituitary-ovarian axis in depressed women. Arch Gen Psychiatry 2000;57:1157-62.

10. Bäckström T, Andersson A, AndreÉ L, Birzniece V, Bixo M, Björn I, Haage D, Isaksson M, Johansson IM, Lindblad C, Lundgren P. Pathogenesis in menstrual cycle- linked CNS disorders. Ann NY Acad Sci 2003;1007(1):42-53.

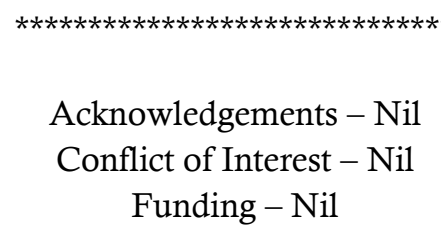

